\title{
Education Management Approach for Information Processing Ability in Cognitive Psychology Subject for Magister Students
}

\author{
Nirwana* \\ Physics Education Study Program, FKIP, University of Bengkulu \\ ${ }^{*}$ Corresponding author. Email: nirwana.adlan@unib.ac.id
}

\begin{abstract}
The thought process is complex and it cannot be seen directly how the brain works and information is processed. Information received through the senses will be felt by the parts that function specifically. On the other hand, activities in collecting or receiving stimuli from the setting, organizing data, solving problems, discovering concepts, and using verbal and visual symbols are called information processing. To improve this process, classroom education management must be implemented to improve the learning process outcomes. Management education can be defined as a series of process activities that manage the way students teach in terms of processes by arranging, constructing, coordinating or controlling, and assessing exercises. Whereas learning management from a limited perspective is characterized as exercises that should be overseen by teachers during collaboration with understudies in the usage of studying and information processing. This recent study shows how the ability to process information in terms of educational management in the Masters in Mathematics Education students. In particular, this study looked at the results of implementing instruments in the Cognitive Psychology subject in the classroom. This research used educational instruments designed to support the research process. The results of research on understanding the material with an average value of 64 in cycle I, 73.3 in cycle II, and 82.7 in cycle III. The absorption power of students in cycle I was $64 \%$, cycle II was $73.3 \%$, and cycle III was $82.7 \%$, and learning completeness in cycle I was $65 \%$, cycle II was $85 \%$, and cycle III was $100 \%$.
\end{abstract}

Keywords: Information process, Education Management, Cognitive Psychology, Master Level, Mathematics Students.

\section{INTRODUCTION}

The theory of information-processing way to deal with the investigation of psychological advancement developed from the American exploratory convention in brain research. Developmental psychologists who adopt an information-processing [1]-[3] viewpoint are responsible for mental advancement as far as development changes in the fundamental parts of a kid's brain [4]-[6]. This kind of theory depends on the possibility that people cycle the data they get, not simply react to stimuli. This viewpoint compares the brain with a PC, which is answerable for examining data from the climat. Based on the standard information processing model for mental development, mind machines incorporate consideration systems for contributing data, a memory that attempts to effectively control data, and long-term memory for saving the data that may be utilized later on. This theory examines how as youngsters develop, their cerebrums likewise develop, prompting signs of progress in their capacity to measure and react to the data they get through their senses. This theory underscores a consistent example of development, rather than theories of Cognitive Development [7], [8], for example Jean Piaget, which argues that advancement occurs gradually over time.

Cognitive processes incorporate [9], [10] with insight, acknowledgment, creative mind, recalling, thinking, assessing, reasoning, solving problems, conceptualizing, and arranging. This cognitive process [11]-[13] can emerge from human language, considerations, pictures, and images. The first step is to generate with attention, it permits handling of the data given. Cognitive processing cannot happen without learning, they work connected at the hip to completely 
get data. This theory consolidates both quantitative and qualitative developmental elements [14], [15]. Qualitative development happens through the rise of new systems for data storage and recovery, creating illustrative capacities, (for example, utilizing language to speak to ideas), or acquiring problem-solving rules [9], [16]. An expansion in the information base or the capacity to remember more things in working memory is an example of quantitative change, just as an increment in the intensity of associated intellectual affiliations [17]. Qualitative and quantitative segments frequently collaborate to grow new and more effective techniques for handling frameworks.

Prospective teachers, of course, have a very big role in the success of learning in schools. The students' interests, abilities, and potentials will not develop optimally without the help and motivation from the teacher. Educators are required to have broad insights and be able to become facilitators who are tasked with providing convenience in learning to all students so that they can learn in an atmosphere that is fun, happy, full of enthusiasm, and dares to express their opinions openly.

At the appointed time, new teacher candidates enter a fairly important stage, namely taking a competency test. This competency test material is related to professional skills [18]. Teachers also have to be creative in designing learning materials, learning resources, and using interesting media [4], [19]. The implementation of student management starts from:

1) Planning, namely the administrative requirements that new prospective students must meet, including sufficient age requirements,

2) Organizing, namely the process of admitting new students carried out by administrative staff who are assisted by teachers in turns and on a scheduled basis,

3) Actuating, namely building student discipline in obeying the rules and protecting the school environment,

4) Controlling (supervision), namely supervision of student discipline both in terms of attendance and habituation.

Management functions [20] in the information process starting from:

1) Planning, namely the learning implementation plan (RPP), the subject design per unit will be applied by the teacher in classroom learning. Based on this lesson plan, a teacher is expected to be able to implement programmed learning. Therefore, RPP must have high applicable power. RPP has a planning function and a learning implementation function. As a function of RPP planning, it encourages teachers to be more prepared to carry out learning activities with careful planning. In implementation, the lesson plan functions to make the learning process effective according to what was planned.

2) Organizing, related to class management. Management of certain classes that include competency standards, basic competencies, subject matter, learning activities, competency achievement, indicators for assessment, time allocation, and learning resources.

3) Actuating, the implementation of systemic learning that is used specifically based on learning and teaching theories to ensure the quality of learning. In implementing learning, things that must be considered are the quality of scientific answers, relevant (coverage, depth, level of difficulty and order of presentation in the syllabus according to the level of physical, intellectual, social emotional and spiritual development of students), systematic (the existing components are interrelated), consistency (not easy to change), adequate (supporting student competence), actual and contextual (according to circumstances), flexible (able to accommodate student diversity), and comprehensive (covering the cognitive, psychomotor, affective domains).

4) Controlling (supervision), namely reporting the results of the implementation of learning or what is known as evaluation. Evaluation in education can provide an overview of the level of student mastery of a material, provide an overview of student learning difficulties, and provide an overview of the student's position among classmates.

Several studies have indicated that people with high working memory are better ready to sift through insignificant data. Specifically, in one examination on the focus on dichotic listening [21], [22], members played two soundtracks, one in each ear, and requested to focus on just one. It shows that there is a critical positive relationship between working memory capacity and the capacity of members to channel data from other soundtracks. Therefore, in this study, the researcher will raise the problem of the existing information processing ability of mathematics master students.

\section{METHODOLOGY}

\subsection{Location}

This research was carried out on the first semester students of the S2 mathematics education study program at FKIP Bengkulu University. The action was carried out by the lecturer who cared for the philosophy of mathematics, assisted by 2 students. Students selected as observers in this action research were the fourthsemester students who have taken the Cognitive Psychology course and received excellent grades [14], 
[23]. To answer the problems in this study, there are several factors that were investigated:

a) Student factors, to see the activeness and learning outcomes of students in using computers as learning media, which means that they are seen directly at the time and after the learning is carried out. Learning outcomes will be seen through the test results in each cycle. While the process seen through the learning process takes place by means of observation in each cycle.

b) Lecturer factors, to see how the Cognitive Psychology learning material prepared in planning and implementing actions uses computers as a medium. In this case, what will be seen is the learning process used in carrying out every action.

\subsection{Research Plan}

The Procedure of this Classroom Action Research consisted of 3 cycles[24][25], [26]. Each cycle was done as per the progressions to be accomplished, such as what has been designed in the factors to be investigated. To see students learning outcomes using computers as learning media, learning outcomes tests were made in each cycle. The implementation of this classroom action research used the accompanying strategies: (1) planning, (2) implementation of action, (3) observation and evaluation, (4) reflection. The clarity of this action research procedure can be described as follows:

\subsubsection{Planning}

Action planning to be carried out in this research were:

a. Creating learning scenarios and selecting subconcepts that can use computers as learning media.

b. Designing and creating an animation program that will be used in the implementation of the action.

c. Make observation sheets to see learning activities in class when using computers as learning media.

d. Designing an evaluation tool to see whether the use of computers as a learning medium can increase the activities and results of learning the philosophy of mathematics.

\subsubsection{Execution of Actions}

Table 1. Indicators
At this stage, the action was carried out in accordance with the planned learning scenario.

\subsubsection{Observation and Evaluation}

At this stage, observation and evaluation of the implementation of the action were carried out using observation sheets and tests in each cycle.

\subsubsection{Reflection}

The outcomes got during the previous stage were collected and analyzed. The results of the analysis were used to determine the action in the next cycle.

\subsection{Data Collection}

The types of data obtained were quantitative and qualitative data consisting of:

1. Test of learning outcomes,

2. Observation sheet.

The data from the student were collected by these activities:

a. The learning outcomes data were obtained by giving a test at the end of each cycle to students.

b. Data about the process, in this case learning activities, were obtained when the action was carried out using observation sheets which were observed by 2 research lecturers and 1 student.

c. Data on student responses to the use of computers as a learning medium for the philosophy of mathematics education was obtained through a questionnaire.

\subsection{Performance Indicators}

The criterion for the level of success of this study is in accordance with the objectives of this study, namely: to increase the activity and learning outcomes of Mathematics Education Master Program students using computers as a medium of learning mathematics philosophy. The indicator of the success of this study is if students can pass with A and B grades of $70 \%$. Meanwhile, the value determination carried out is in accordance with the assessment carried out at the University of Bengkulu as follows:

\begin{tabular}{|l|l|l|l|}
\hline Condition & Range & Annotation & Mark \\
\hline If the student is successful & $80 \%-100 \%$ & Excellent & $\mathrm{A}$ \\
\hline If the average student is successful & $70 \%-79 \%$ & Very Good & $\mathrm{B}$ \\
\hline If the average student is successful & $56 \%-69 \%$ & Good & $\mathrm{C}$ \\
\hline If the average student is successful & $46 \%-55 \%$ & Less Good & $\mathrm{D}$ \\
\hline If the average student is successful & $<45 \%$ & Failed & $\mathrm{E}$ \\
\hline
\end{tabular}




\section{RESULT AND DISCUSSION}

Students learning outcomes are viewed from the aspects of understanding the material and student scientific performance in learning through the application of POAC in the philosophy of mathematics education. Then it will be seen that students learning outcomes actuating the improvement for each cycle. Learning outcomes in the aspect of understanding the material were obtained from a combination of cycle test scores and group reports, where $70 \%$ were obtained from cycle tests and $30 \%$ from group reports. The learning outcomes of students' understanding of the material actuated the improvement in each cycle.

\subsection{First Cycle}

The observation results of teaching activities are shown in table 2 and observations are made by 1 observer, namely the teacher. Observations were made by using a guideline or assessment criteria for the teaching activity observation sheet and the criteria for assessing the cognitive psychomotor observation sheet and student activity. On the observation sheet, the observer is given insufficient, sufficient, and good answer choices for each aspect being observed.

Table 2. Teaching Activities Observation

\begin{tabular}{|l|l|l|}
\hline No & Skills & Opportunities For Improvement \\
\hline 1 & $\begin{array}{l}\text { Phase 1 } \\
\text { Planning }\end{array}$ & $\begin{array}{l}\text { Teachers pay less attention to others who do not comprehend the presentation of } \\
\text { the issues raised. } \\
\text { The instructor only guides a few groups which amplify the difficulty in } \\
\text { carrying out the investigation. }\end{array}$ \\
\hline 2 & $\begin{array}{l}\text { Phase 2 } \\
\text { Actuating }\end{array}$ & $\begin{array}{l}\text { There were three groups that did not have the opportunity to investigate } \\
\text { perfectly because of lack of attention. It happened because time had been spent } \\
\text { guiding other groups. }\end{array}$ \\
\hline
\end{tabular}

The observer gave an assessment based on the provisions of the teacher observation assessment criteria in cycle I. In general, the scores obtained from the observer for teaching activities in teaching showed that the teaching activity in applying POAC to Cognitive Psychology material was included in the good criteria, but in the learning process, there were still some teacher shortcomings which can be seen in table 3 .

Table 3. Improvement for Teacher

\begin{tabular}{|c|c|c|}
\hline No & Skills & Opportunities For Improvement \\
\hline 1 & $\begin{array}{l}\text { Phase } 1 \\
\text { Planning }\end{array}$ & $\begin{array}{l}\text { Students are less active in making conclusions, this is because students are } \\
\text { confused when asked to make conclusions. } \\
\text { Students do not know what is important and necessary, this is because } \\
\text { students still feel that all knowledge comes from teachers and educators. }\end{array}$ \\
\hline 2 & $\begin{array}{l}\text { Phase } 2 \\
\text { Actuating }\end{array}$ & $\begin{array}{l}\text { There are still many students who work together when working on } \\
\text { assignments. Many students are less and lazy to read when working on } \\
\text { assignments. }\end{array}$ \\
\hline
\end{tabular}

\subsection{Second Cycle}

In cycle II student learning outcomes are better than cycle I, and in cycle III student learning outcomes are better than cycle II. This shows that student learning outcomes are good. It is clear that student learning completeness during learning through the application of POAC also increases in each cycle.

Table 4. Student Activity Data in Cycle I

\begin{tabular}{|l|l|l|}
\hline No & \multicolumn{1}{|c|}{ Skills } & Opportunity For Improvement \\
\hline 1 & Data Analysis & Many students do not match the expected analysis. \\
\hline 2 & Conclude & $\begin{array}{l}\text { Students are less active in making conclusions. There are still students who do not know } \\
\text { what is important and necessary, this is because students still feel that all knowledge } \\
\text { comes from teachers and educators. }\end{array}$ \\
\hline 3 & Problem Tasks & There are still many students who work together when working on assignments. \\
\hline
\end{tabular}

Table 4 describes the student activity data in cycle I. In general, the scores obtained from observers for student activities in teaching are included in good criteria. This means that in following the learning 
process there are still shortcomings that need to be fixed

in the next cycle, including in Table 5.

Table 5. Improvement for Cycle II

\begin{tabular}{|c|c|c|}
\hline No & Phase & Opportunity For Improvement II \\
\hline 1 & $\begin{array}{l}\text { Phase } 5 \\
\text { Organizing }\end{array}$ & $\begin{array}{l}\text { Students and their groups who have difficulty carrying out investigations. There are some } \\
\text { groups that do not have the opportunity to investigate perfectly because of lack of } \\
\text { attention, but because time has run out }\end{array}$ \\
\hline 2 & $\begin{array}{l}\text { Phase } 6 \\
\text { Controlling }\end{array}$ & $\begin{array}{l}\text { Students have not dared to present learning results } \\
\text { Understudies are less active in reacting and requesting the outcomes from the } \\
\text { conversation. }\end{array}$ \\
\hline
\end{tabular}

After carrying out the process of teaching and learning by adjusting POAC to the mathematics education philosophy material at the end of the second cycle, a reflection was made of the outcomes got both from the perception sheet and from the cycle II test. To upgrade the viewpoints that are as yet ailing in the second cycle, it is important to find a way to be executed in the following cycle.

From some data conducted by observers on student cognitive, it was obtained an average score of 10 so it was classified as good criteria. This is because the deficiencies in the first cycle have been fixed, but in cycle II still any deficiencies. To upgrade the perspectives that are as yet ailing in the second cycle, it is important to make upgrades that should be made by understudies in the third cycle. The improvements that have to be made were: 1) The educator guides understudies to dissect information cautiously so the outcomes are as expected, 2) guides understudies to have the option to give all information identified with the material so understudies know significant focuses that should be concluded, 3) The educator gives an admonition to understudies not to work together with other when working on tasks.

From the data conducted by observers on student activities, good criteria are obtained. This is because the deficiencies in the first cycle have been fixed, but apart from that, there are still deficiencies that need to be fixed. To increase the viewpoints that are as yet ailing in cycle II, it is important to make improvements that must be made by students in cycle III. The improvements which have to be made include: 1) students manage time so that each student who is conducting an experiment has enough time, 2) students do not rely on their group members to work alone and do not copy the work of other group members, 3) students are more active in concluding and skilled in using his abilities.

\subsection{Third Cycle}

From observers' observations of the teaching activity, an average score of 32 was obtained, so it was classified as good. The teacher has made improvements to items that are included as sufficient criteria in cycles I and II. However, from the results of these observations, there is still an adequate assessment because in the teaching and learning process there are always weaknesses or shortcomings, namely, the teacher motivates students about the importance of working together when working and so that students are more enthusiastic in learning and discussing so that the class becomes more active. However, from the results of the test cycle III, it can be concluded that these deficiencies do not really affect the learning process.

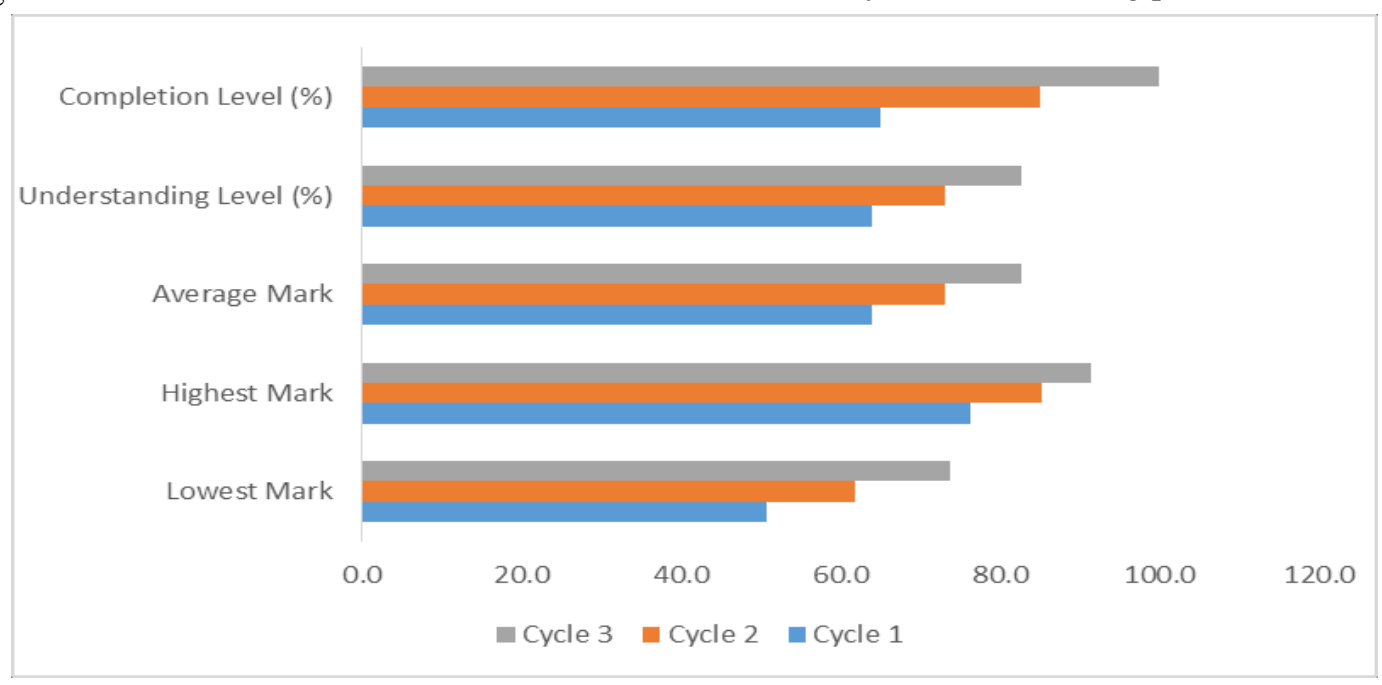

Figure 1 Improvement Level for Every Cycle. 
From the data conducted by observers on student activity, it was obtained an average score of 11 so it was classified as good criteria. This is because the deficiencies in cycle II have been fixed, although there are deficiencies in cycle II, but it has no effect on the cognitive achievement of student processes. The achievement of completeness in cycle III is due to the teacher having reflected on cycle II, namely: 1) The educator guides understudies to dissect information cautiously so the outcomes are as expected, 2) guides understudies to have the option to recall the material so understudies know significant focuses that should be concluded, 3) The educator gives an admonition to understudies not to work together with other when working on tasks.

The expansion in each cycle (Figure 1) was brought about by a few elements, including 1) Teachers have an effort to implement the best possible POAC, 2) Teachers have an effort to improve the inadequacies that happened in cycle I and II and also implement it better in cycle III, 3) in the third cycle understudies give more consideration to the exercise, in the trial, they are additionally more intrigued and eager in examining the material of o the philosophy of mathematics education.

The increase was that in the first cycle, the average value of 64 increased to 73.3 in the second cycle and increased again to 82.7 in the third cycle. In cycle I, only 22 of 34 students scored $\geq 65$ or $65 \%$ (not yet completed), in cycle II it increased to 29 students who scored $\geq 65$ or by $85 \%$ (complete), while in cycle III all students got grades $\geq 65$ or by $85 \%$ in the first cycle (complete).

\section{CONCLUSION}

In view of the results and discussion of this research, it can be concluded that learning the philosophy of mathematics education by implementing POAC could expand understudy learning activities in the Mathematics Education Study Program at FKIP, Bengkulu University. This can be seen from the expansion in understudy learning exercises in every cycle performed in this research. The average score of student learning activities in the first cycle was 28 in the sufficient category, then increased in the second cycle to 32 in the good category, then increased again in the third cycle to 35 in the good category. Furthermore, learning the philosophy of mathematics education by implementing POAC can improve student learning activities in the Mathematics Education Study Program at FKIP, Bengkulu University, namely understanding the material with an average value of 64 in cycle I, cycle II of 73.3, and cycle III of 82.7. The absorption power of students in cycle I was $64 \%$, cycle II was $73.3 \%$, and cycle III was $82.7 \%$, and learning completeness in cycle I was $65 \%$, cycle II was $85 \%$, and cycle III was $100 \%$.

\section{REFERENCES}

[1] S. Sinanović and D. H. Johnson, "Toward a theory of information processing," Signal Processing, vol. 87, no. 6, 2007, doi: 10.1016/j.sigpro.2006.11.005.

[2] J. A. Bergou and M. Hillery, "Introduction to the Theory of Quantum Information Processing," Introd. to Theory Quantum Inf. Process., 2013.

[3] P. Kok, "Photonic quantum information processing," Contemp. Phys., vol. 57, no. 4, 2016, doi: 10.1080/00107514.2016.1178472.

[4] D. Ebaid and S. G. Crewther, "Visual information processing in young and older adults," Front. Aging Neurosci., vol. 11, no. MAY, 2019, doi: 10.3389/fnagi.2019.00116.

[5] "Understanding different graphic legends information in the process of learning," Teh. Vjesn. - Tech. Gaz., vol. 23, no. 5, 2016, doi: $10.17559 / \mathrm{tv}-20150310102017$.

[6] M. Albertus, "Raking-ratio empirical process with auxiliary information learning," ESAIM - Probab. Stat., vol. 24, 2020, doi: 10.1051/ps/2020017.

[7] T. Sekiyama, "The Impact of the Fourth Industrial Revolution on Student Mobility from the Perspective of Education Economics," Creat. Educ., vol. 11, no. 04, 2020, doi 10.4236/ce.2020.114031.

[8] L. P. Steffe and T. Kieren, "Radical Constructivism and Mathematics Education," $J$. Res. Math. Educ., vol. 25, no. 6, 2020, doi: 10.5951/jresematheduc.25.6.0711.

[9] G. Piccinini and A. Scarantino, "Information processing, computation, and cognition," Journal of Biological Physics, vol. 37, no. 1. 2011, doi: 10.1007/s10867-010-9195-3.

[10] T. J. Rudolph and E. Popp, "An information processing theory of ambivalence," Polit. Psychol., vol. 28, no. 5, 2007, doi: 10.1111/j.14679221.2007.00590.x.

[11] Y. Wang and G. Ruhe, "The Cognitive Process of Decision Making," Int. J. Cogn. Informatics Nat. Intell., vol. 1, no. 2, 2007, doi: 10.4018/jcini.2007040105.

[12] J. B. Jarecki, J. H. Tan, and M. A. Jenny, "A framework for building cognitive process models," Psychon. Bull. Rev., vol. 27, no. 6, 2020, doi: 10.3758/s13423-020-01747-2.

[13] I. W. Widiana, I. N. Jampel, and I. P. Prawini, "The Effectiveness of Traditional Game-Based Communication Learning Activity for Cognitive Process Dimension Learning Achievement," 
Cakrawala Pendidik., vol. 37, no. 2, 2018.

[14] S. Ra, U. Shrestha, S. Khatiwada, S. W. Yoon, and K. Kwon, "The rise of technology and impact on skills," Int. J. Train. Res., vol. 17, no. sup1, 2019, doi: 10.1080/14480220.2019.1629727.

[15] S. M. bin Ismail and W. A. A. W. Haniff, "Education 4.0: The Effectiveness of VARK Learning Style towards Actualising Industrial Revolution 4.0," J. Educ. Soc. Res., vol. 10, no. 3, 2020, doi: 10.36941/jesr-2020-0045.

[16] H. Zhou, "An empirical test of the information processing theory," Int. J. Inf. Syst. Supply Chain Manag., vol. 4, no. 1, 2011, doi: 10.4018/jisscm.2011010103.

[17] D. Gardner and L. Miller, "Managing self-access language learning: Principles and practice," System, vol. 39, no. 1, 2011, doi: 10.1016/j.system.2011.01.010.

[18] A. Bauer, “Assessment of educational systems and educational management: Theoretical contributions," Educ. Real., vol. 44, no. 1, 2019, doi: 10.1590/2175-623677006.

[19] D. W. Embley, "Toward semantic understanding: an approach based on information extraction ontologies," in Proceedings of the 15th Australasian database ..., 2004, vol. 27, no. Winslett, pp. 3-12, [Online]. Available: http://dl.acm.org/citation.cfm?id=1012295\%5Cnht tp://dl.acm.org/citation.cfm?id=1012295\&CFID=3 $9721657 \&$ CFTOKEN=31041608.
[20] M. Somantri, "Research Areas In The Development of Educational Management," Int. J. Educ. Manag. Innov., vol. 1, no. 2, 2020, doi: 10.12928/ijemi.v1i2.1684.

[21] M. Scott, "Interaural recalibration of phonetic categories," J. Acoust. Soc. Am., vol. 147, no. 2, 2020, doi: 10.1121/10.0000735.

[22] P. Shree, P. Swami, V. Suresh, and T. K. Gandhi, "A novel technique for identifying attentional selection in a dichotic environment," 2017, doi: 10.1109/INDICON.2016.7838885.

[23] N. M. Rege Colet, "From content-centred to learning-centred approaches: shifting educational paradigm in higher education," J. Educ. Adm. Hist., vol. 49, no. 1, 2017, doi: 10.1080/00220620.2017.1252737.

[24] S. P. Purohman, "Classroom Action Research Alternative Research Activity for Teachers," Res. Gate, no. June, 2018.

[25] P. Meesuk, B. Sramoon, and A. Wongrugsa, "Classroom Action Research-based Instruction: The Sustainable Teacher Professional Development Strategy," J. Teach. Educ. Sustain., vol. 22, no. 1, 2020, doi: 10.2478/jtes-2020-0008.

[26] S. Khasinah, "Classroom Action Research," $J$. Pionir, Vol. 1, Nomor 1, vol. 1, no. 2, 2013. 